\title{
AS ARTES NOS ÚLTIMOS 20 ANOS
}

Quais foram as principais transformações das artes no cenário brasileiro nos últimos 20 anos? Para responder a essa pergunta o Centro Universitário Maria Antonia convidou, em 2013, ano em que completou duas décadas de existência, artistas e críticos de diversas áreas da cultura. Em encontros realizados de agosto a dezembro do ano passado, Paulo Mendes da Rocha (arquitetura), Lorenzo Mammì (música), Nuno Ramos e Moacir dos Anjos (artes visuais), Antonio Cicero (poesia), Franklin Leopoldo e Silva (filosofia), Manuel da Costa Pinto (literatura) e Ismail Xavier (cinema) destacaram as mudanças nos aspectos da produção de suas respectivas áreas e as transformações ocorridas em cada uma delas nos últimos vinte anos. Abaixo, um resumo e trechos de vídeos de cada uma das palestras. Os vídeos da íntegra de cada um dos encontros serão disponibilizados, semanalmente, a partir do dia 3 de junho, na página da revista Celeuma no Facebook.

\section{CINEMA}

Crítico e professor de cinema, Ismail Xavier apresentou as transformações técnicas e temáticas sofridas pela indústria cinematográfica, destacando o caso brasileiro. Há 20 anos, segundo ele, o cinema nacional saía de uma crise provocada durante governo Collor onde, até meados de 1993, sofria com problemas de produção causados pelo fim da Embrafilme.

De 94 em diante, a criação de uma série de incentivos culturais como a Lei do Audiovisual, a Lei Rouanet e também o aumento do investimento dos produtores em gêneros mais populares como a comédia, barateou os custos de produção, o que iniciou a chamada "retomada do cinema nacional".

Dentro deste espectro, Xavier também destacou o caráter independente de parte da atual produção do cinema paulistano e, também, o criativo e importante período que o cinema pernambucano vem vivenciando. 


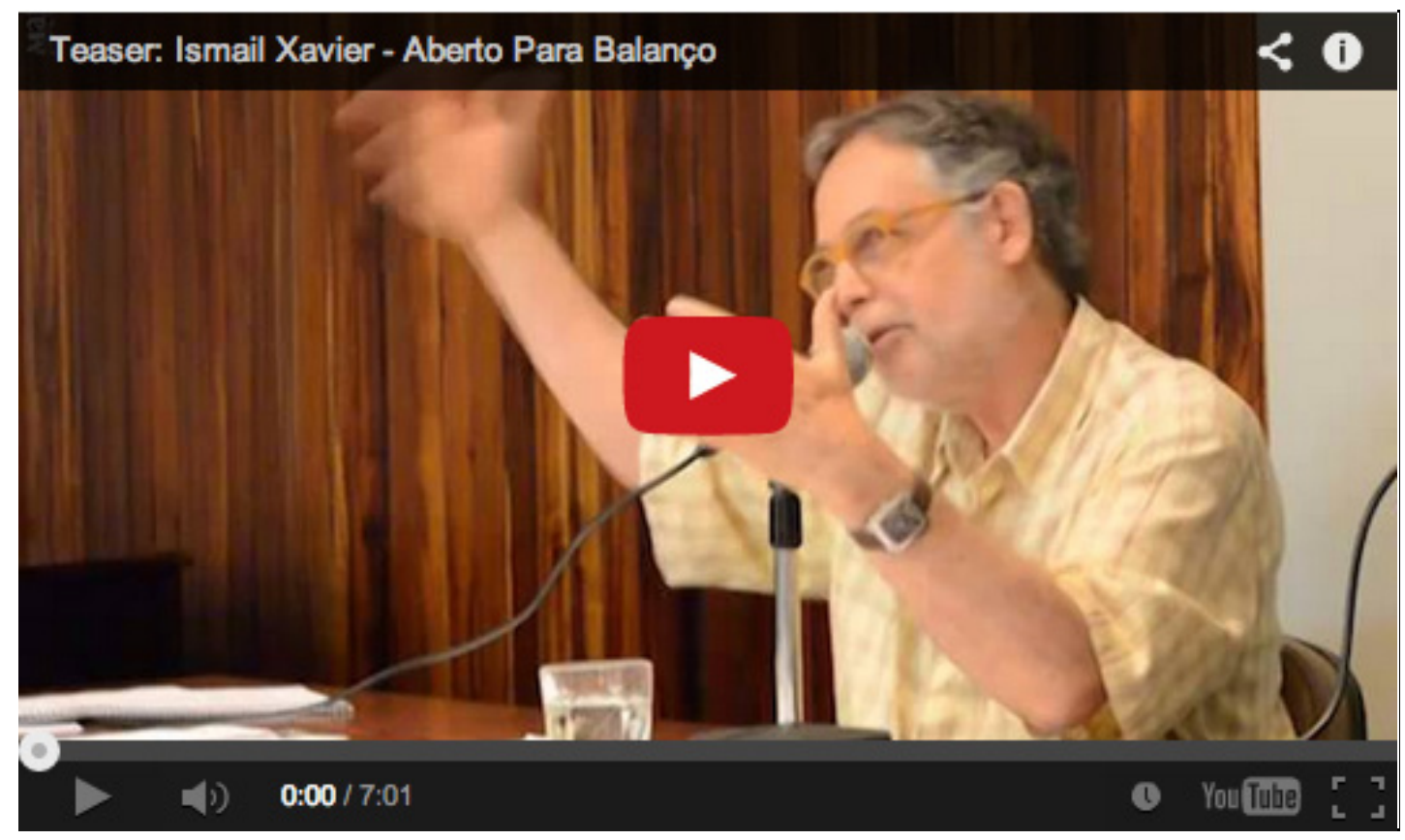

\section{ARTES VISUAIS}

A fala de Nuno Ramos traçou distinções entre arte moderna e arte contemporânea sob o ponto de vista do público e do artista. Segundo ele, há "dificuldade de assimilação crítica" e de recepção dos trabalhos contemporâneos, algo que não ocorria tão explicitamente nos trabalhos modernos. "Na arte moderna, ações e reações são muito imbricadas; na arte contemporânea a borda da linguagem não é tão clara para quem faz [o trabalho]", disse.

Para Nuno, a produção na arte contemporânea vem utilizando técnicas e esquemas facilmente detectáveis como, por exemplo, o fato de guiar-se por exterioridades discursivas (questões éticas, de gê cas, etc). 


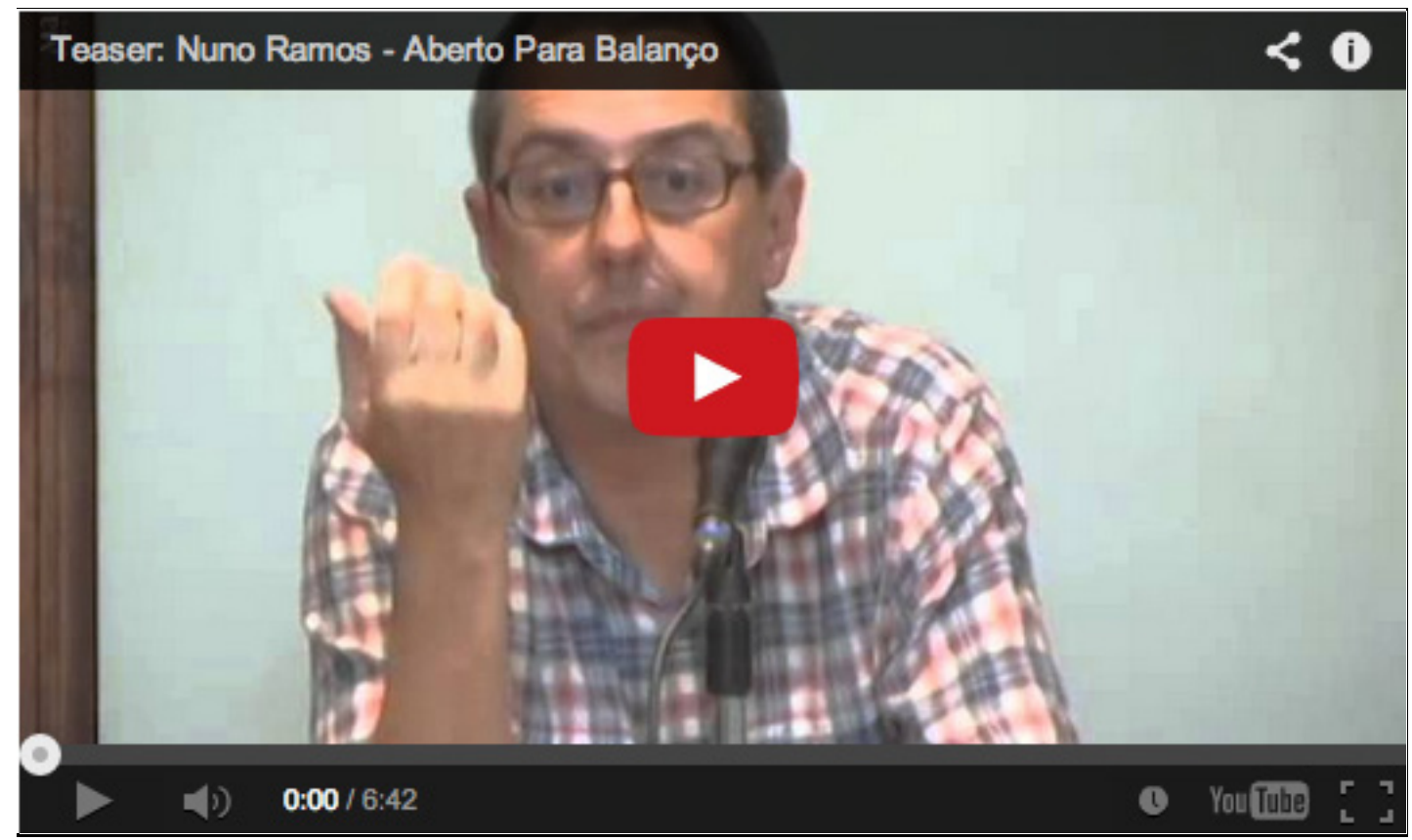

Pesquisador e curador, Moacir dos Anjos destacou as transformações sociais e econômicas do país nos últimos vinte anos. Ele apontou uma série de contradições, como o fato de os índices de inflação, desemprego e analfabetismo terem caído e, ainda assim, haver injustiças sociais explícitas, como a violência no campo e comunidades excluídas de benefícios sociais.

A partir daí ele introduziu sua ideia de representação artística baseando-se em três aspectos:

A representação partida, que não leva em conta o "caráter fraturado do país" e que contribui para a ideia estereotipada da nação (trabalhos que primam pelo valor estético, sem preocupações sociais);

A representação contraditória, que lida com as diferenças sociais através de aspectos mais subjetivos, como a fragilidade dos materiais;

E a representação das sobras, que nomeia os danos, faz denúncias moralizantes e tem capacidade de individualizar os excluídos. 


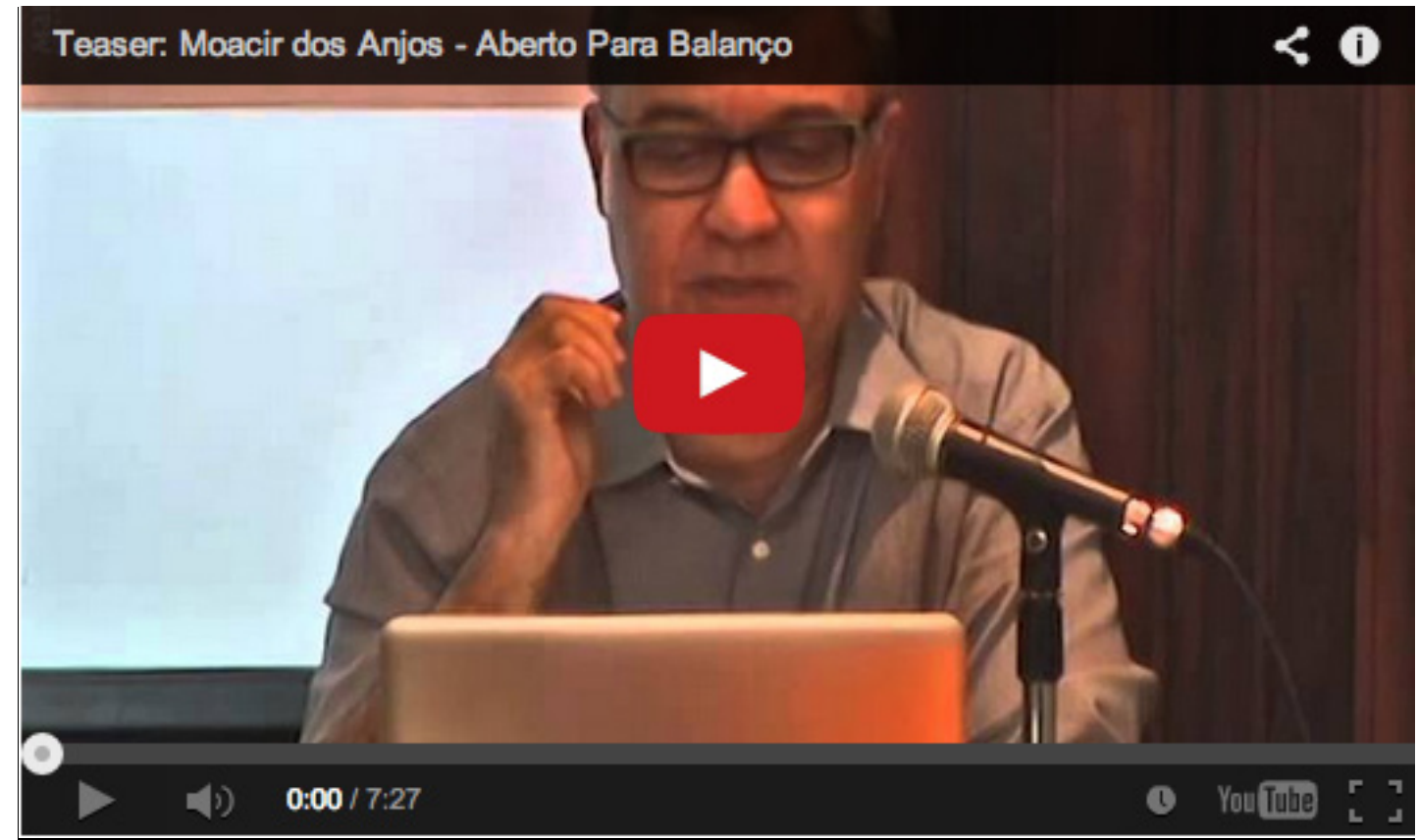

\section{ARQUITETURA}

Um dos nomes mais importantes para a arquitetura moderna brasileira, Paulo Mendes da Rocha destacou a importância histórica do prédio do Centro Universitário Maria Antonia e criticou a transformação do ensino da arquitetura no Brasil que, em parte, segundo ele, se voltou para a "formação de jovens treinados para fazer prédios comuns ou conjuntos habitacionais".

$\mathrm{O}$ arquiteto apresentou também alguns projetos de grande porte para a cidade, como a planta de uma nova Praça da República. 


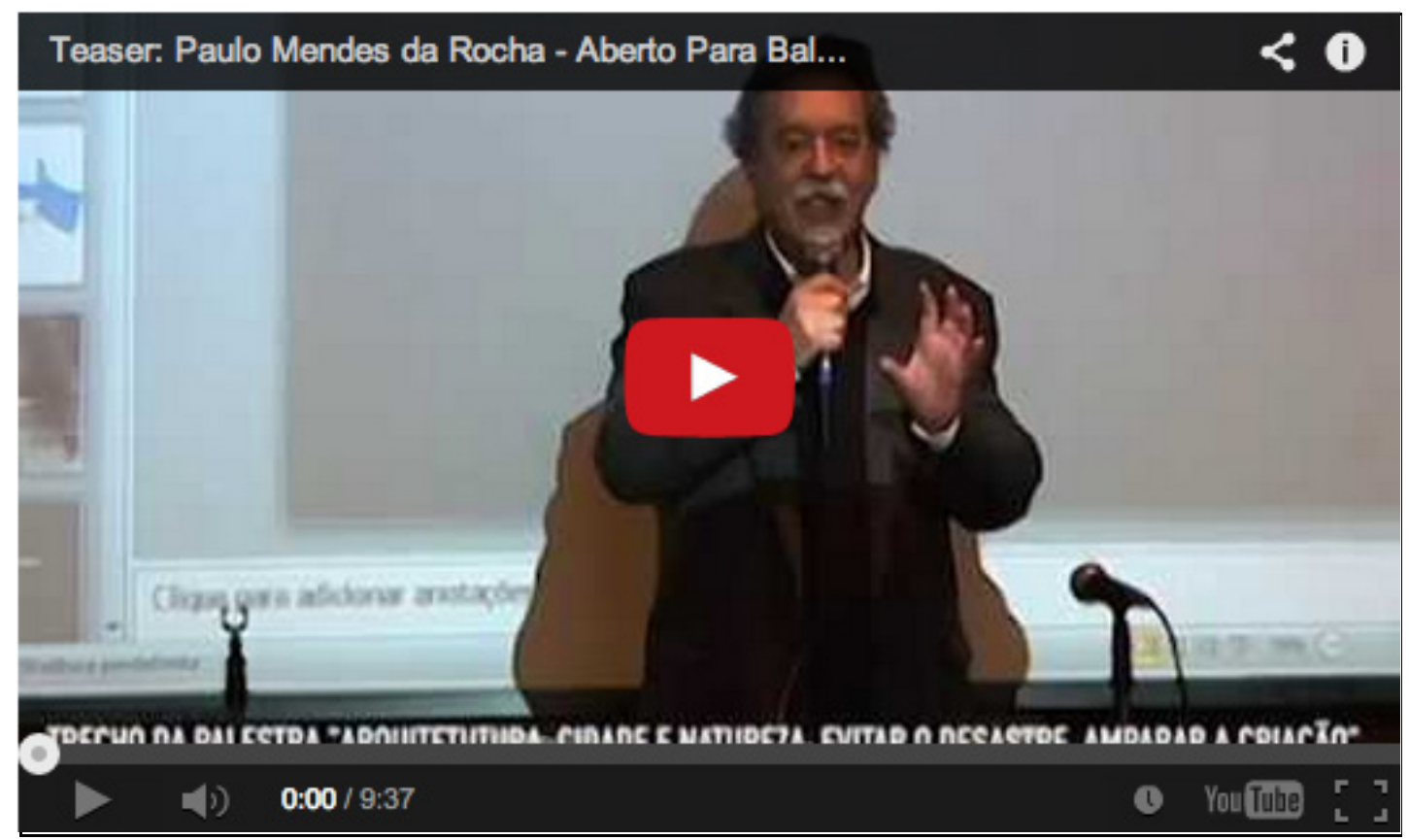

\section{MÚSICA}

Intitulada "O fim do disco", a palestra de Lorenzo Mammì tratou das transformações no modo como se ouve música desde a década de 40, destacando a presença do rádio nos lares deste período até, posteriormente, a inserção da "cultura do disco": "os discos eram escolhas existenciais, eram objetos que comportavam relações complexas”, disse.

Ele chamou atenção para o fato de o CD nunca haver se desvencilhado do vinil, "apesar do tamanho [de armazenamento] maior, ele guarda o tamanho médio de músicas, como se fosse um vinil em formato miniatura".

Para ele, a era digital tornou mais democrático o acesso à música, porém, a flexibilidade causada por essas novas formas (como, por exemplo, o fato de ser possível comprar individualmente as faixas de um disco), acabou interferindo na "apresentação de uma poética" e dificultando o controle da recepção por parte do autor. 


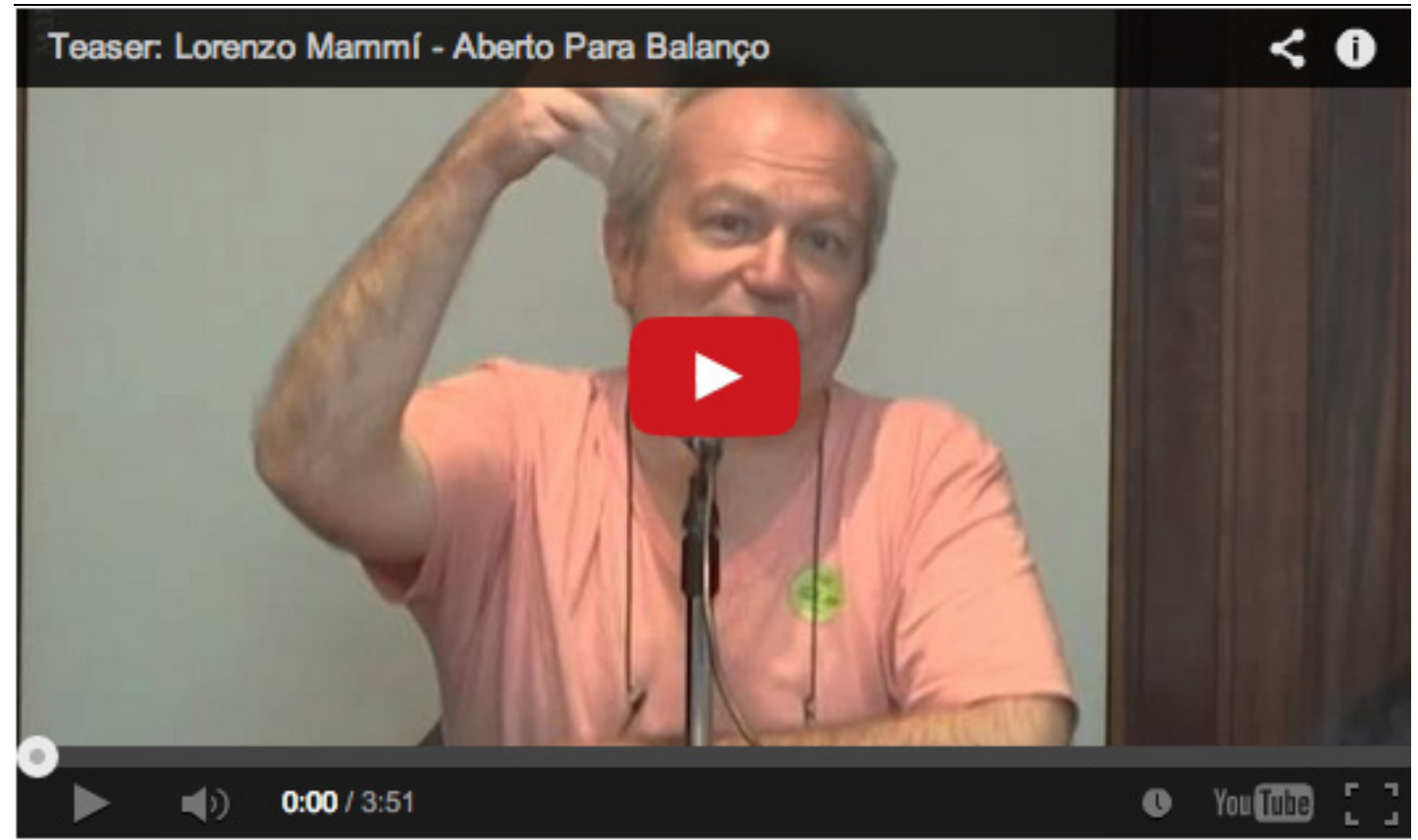

\section{LITERATURA}

A ascensão do mercado editorial no Brasil nos últimos vinte anos em contraste com o baixo índice de leitura e compreensão do brasileiro foi o ponto de partida para a palestra do jornalista Manuel da Costa Pinto. Ele analisou as modificações do formato da critica literária nos cadernos culturais dos jornais e o caráter grandioso que as festas e prêmios literários adquiriram nos últimos anos, algo que contribuiu para a modificação da imagem de alguns escritores, que, segundo ele, assemelham-se hoje a pop stars.

Questões temáticas também foram abordadas, como o fato de que há hoje uma "demanda por uma literatura sem muitas mediações". Disse que existe na produção contemporânea, desde os anos 90, um "realismo fantástico que aborda questões sociais": "há a busca de um caráter surreal da realidade, do bizarro na vida urbana”. 


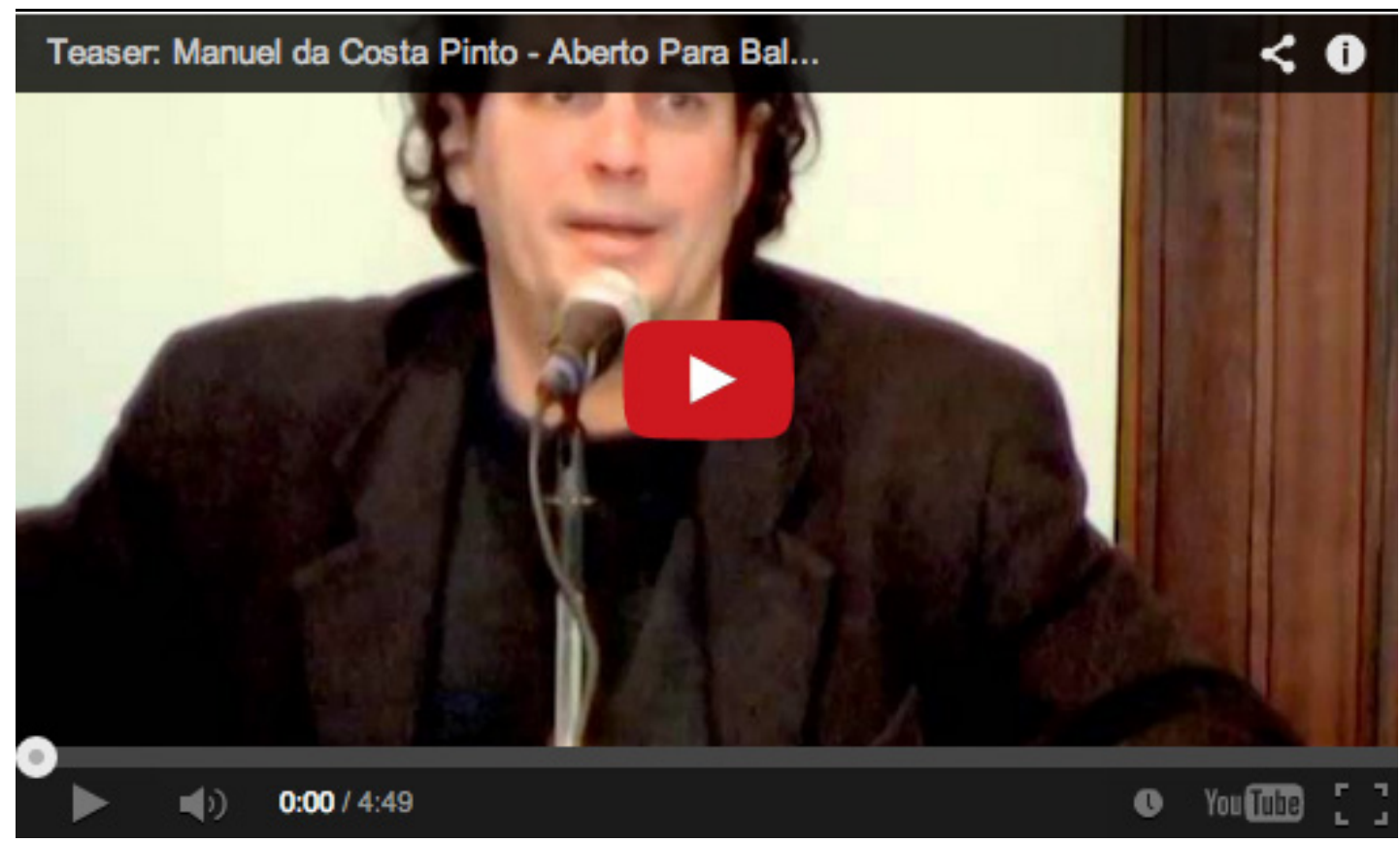

\section{POESIA}

Antonio Cicero contrapôs as características da poesia de vanguarda às da poesia contemporânea. Para ele, há hoje uma rica e "ilimitada pluralidade de formas e meios" na produção poética o que, para alguns críticos, torna essa produção ruim ou não tão esclarecida, disse.

Cicero também comentou o argumento segundo o qual não haveria mais campo para os poemas: "a fruição de um poema demanda mais tempo livre para a apreciação do que outras obras artísticas. Como há pouco tempo livre na nossa sociedade, este acaba sendo o argumento para aqueles que afirmam que não há mais espaço para a poesia". 


celeuna número 4 |maio $2014 \quad 91$

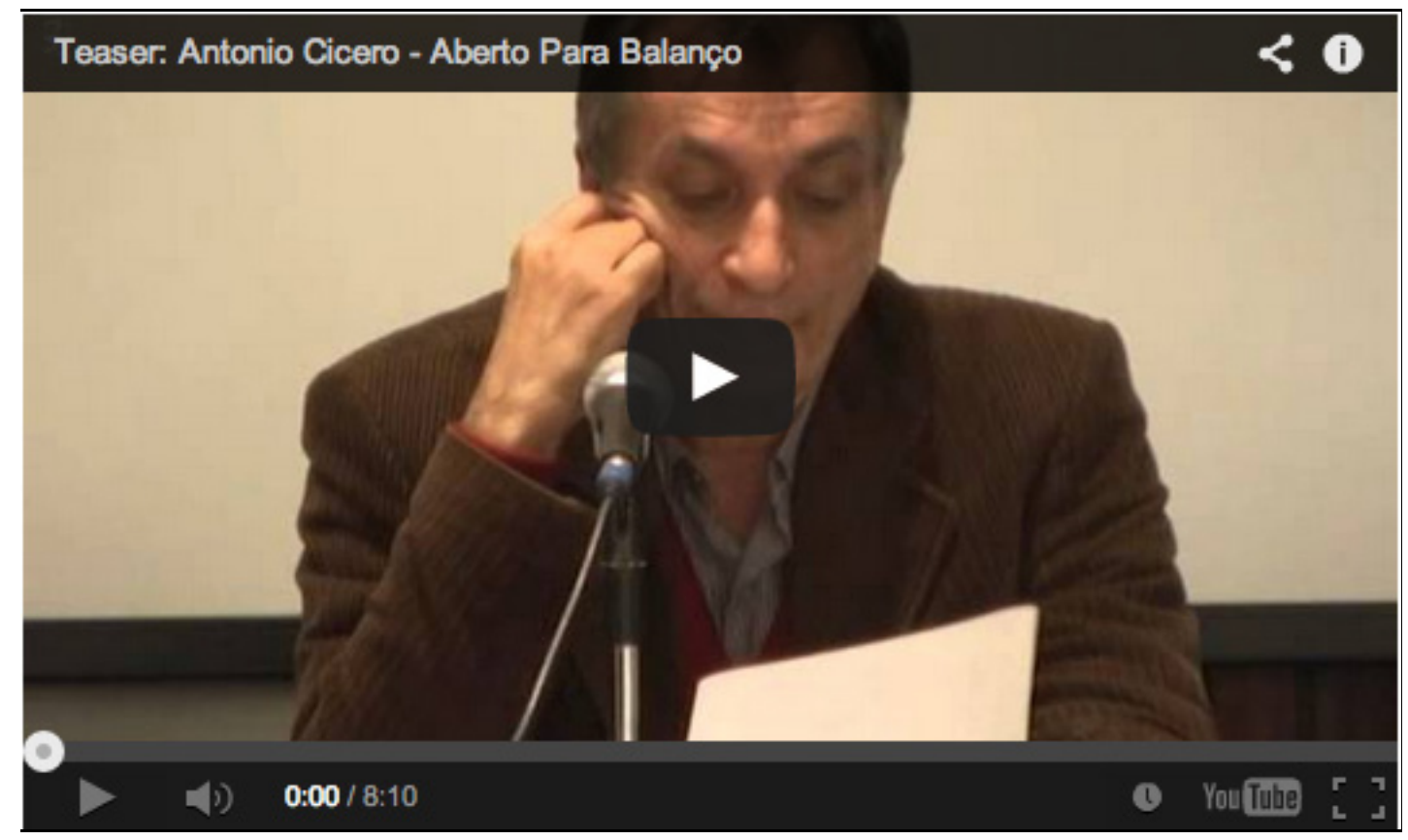

\section{FILOSOFIA}

O filósofo Franklin Leopoldo e Silva discutiu as escolhas temáticas dos cursos da série "Filosofia no centro", realizados no Maria Antonia. Destacou as relações entre literatura, teatro e artes visuais e o pensamento de filósofos antigos e contemporâneos. Também abordou os desafios da filosofia e da crítica na atualidade: "Um dos esforços da filosofia contemporânea é reinventar o pensamento. Quanto mais radical é a crítica, mais radical tem que ser as suas consequências". 


\begin{tabular}{l|l|l} 
celeuna & número 4 | maio 2014 & dossiê \\
\hline
\end{tabular}

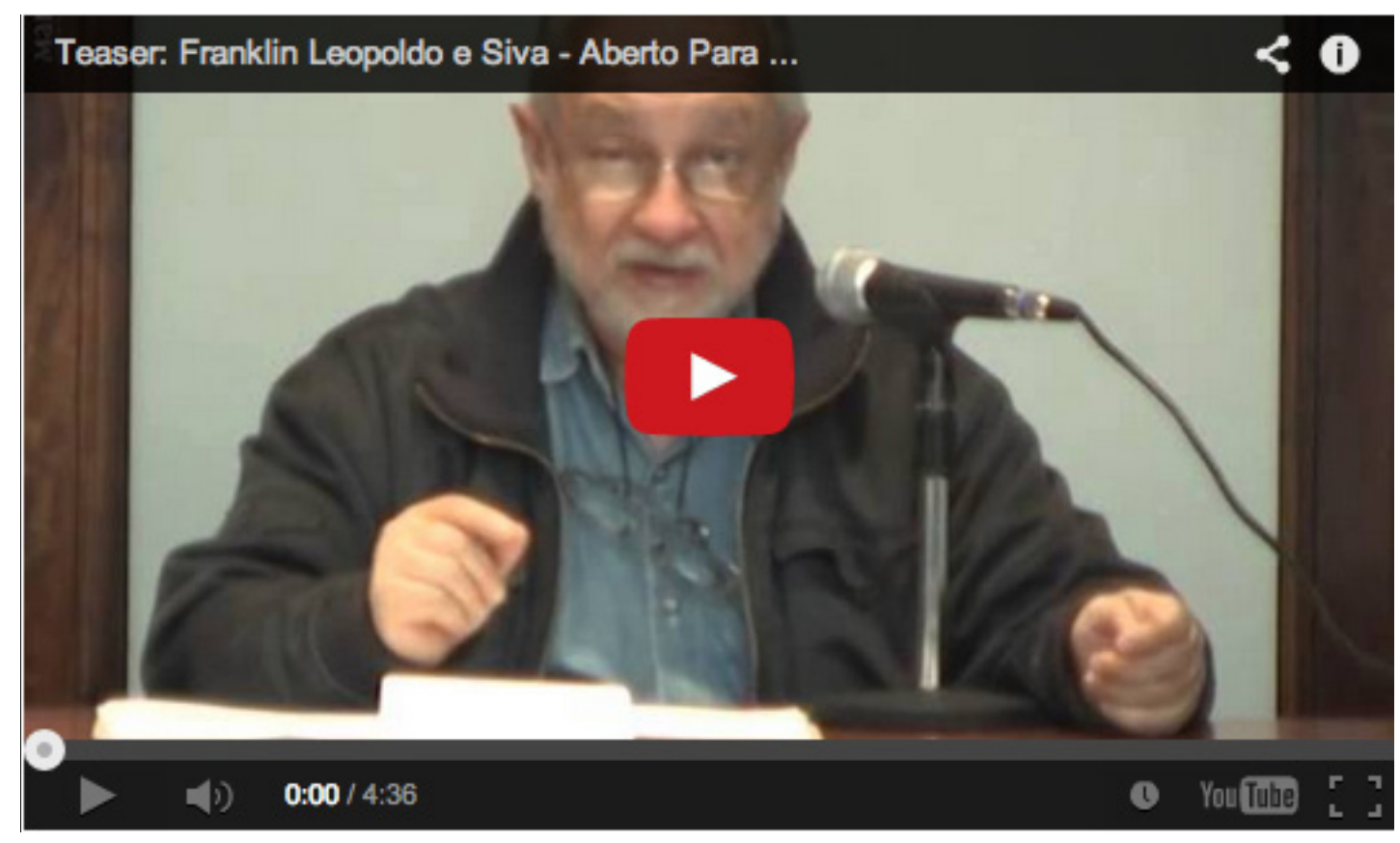

Por Thierry Freitas. 